\title{
Which patients with advanced respiratory disease die in hospital? A 14-year population-based study of trends and associated factors
}

Irene J. Higginson ${ }^{1 *}$, Charles C. Reilly ${ }^{1}$, Sabrina Bajwah ${ }^{1}$, Matthew Maddocks ${ }^{1}$, Massimo Costantini', Wei Gao ${ }^{1}$, on behalf of the GUIDE_Care project

\begin{abstract}
Background: Strategies in many countries have sought to improve palliative care and reduce hospital deaths for non-cancer patients, but their effects are not evaluated. We aimed to determine the trends and factors associated with dying in hospital in two common progressive respiratory diseases, and the impact of a national end of life care (EoLC) strategy to reduce deaths in hospital.

Methods: This population-based observational study linked death registration data for people in England dying from chronic obstructive pulmonary disease (COPD) or interstitial pulmonary diseases (IPD). We plotted age- and sex-standardised trends, assessed during the pre-strategy (2001-2004), first strategy phase (2004-2008), and strategy intensification (2009-2014) periods, and identified factors associated with hospital death using multiple adjusted proportion ratios (PRs).

Results: Over 14 years, 380,232 people died from COPD $(334,520)$ or IPD $(45,712)$. Deaths from COPD and IPD increased by $0.9 \%$ and $9.2 \%$ annually, respectively. Death in hospital was most common (67\% COPD, 70\% IPD). Dying in hospice was rare (0.9\% COPD, 2.9\% IPD). After a plateau in 2004-2005, hospital deaths fell (PRs 0.92-0.94). Co-morbidities and deprivation independently increased the chances of dying in hospital, with larger effects in IPD (PRs 1.01-1.55) than COPD (PRs 1.01-1.39) and dose-response gradients. The impact of multimorbidity increased over time; hospital deaths did not fall for people with two or more co-morbidities in COPD, nor one or more in IPD. Living in rural areas (PRs 0.94-0.94) or outside London (PRs, 0.89-0.98) reduced the chances of hospital death. In IPD, increased age reduced the likelihood of hospital death (PR 0.81, $\geq 85$ versus $\leq 54$ years); divergently, in COPD, being aged 65-74 years was associated with increased hospital deaths (PR 1.13, versus $\leq 54$ years). The independent effects of sex and marital status differed for COPD versus IPD (PRs 0.89-1.04); in COPD, hospital death was associated with being married.

Conclusions: The EoLC strategy appeared to have contributed to tangible reductions in hospital deaths, but did not reach people with multimorbidity and this gap widened over time. Integrating palliative care earlier in the disease trajectory especially in deprived areas and cities, and where multimorbidity is present, should be boosted, taking into account the different demographic factors in COPD and IPD.
\end{abstract}

Keywords: Hospital, Palliative care, End of life care, Chronic obstructive pulmonary disease, Interstitial pulmonary diseases, Interstitial lung disease, Respiratory, Policy, Place of death

\footnotetext{
* Correspondence: irene.higginson@kcl.ac.uk

${ }^{1}$ Cicely Saunders Institute of Palliative Care, Policy \& Rehabilitation, King's

College London, Bessemer Road, London SE5 9PJ, UK

Full list of author information is available at the end of the article
} 


\section{Background}

Chronic diseases and multimorbidity are common and increasing. Respiratory diseases are major contributors, especially chronic obstructive pulmonary disease (COPD) and interstitial pulmonary disease (IPD). More than 3 million people worldwide died of COPD in 2012, representing $6 \%$ of all deaths that year [1]. Mortality from IPDs is climbing, with current age-standardized mortality ranging from 4 to 10 per 100,000 population (highest in UK and lowest in Sweden) [2]. Both conditions result in a high use of hospital services across all medical areas, especially among people in advanced stages, when the systemic effects of disease lead to dependency [3]; this leads to high healthcare costs. UK population-based data on admissions suggests that, in IPD, the estimated financial burden of hospitalisation in 2010 was $£ 16.2$ million per year [4]. Despite this expenditure, there are concerns that care in advanced disease is suboptimal, inadequately co-ordinated, and with patients suffering an average of 14 symptoms, plus psychological and information concerns [5-8]. For most patients with a progressive illness, the hospital is among the least preferred places of death [9].

In the UK, the National Institute of Clinical Excellence (NICE) published Guidance on Supportive and Palliative Care in 2004 [10], and an extra $£ 50$ million was allocated to palliative care services. Building from this Guidance, the End of Life Care (EoLC) Programme was developed to improve care in the last year of life, with a specific goal to reach patients in general medical care and with diseases beyond cancer [11]. Roll out was intensified after 2008 within the EoLC Strategy [12]. The Programme and Strategy prioritised home care as an alternative to hospital, promoting initiatives to elicit preferred place of death and boost support from general practitioners. However, whether policies altered care for those dying from major diseases, apart from cancer $[11,13]$, is unknown. Where people die is a common quality marker. Whilst place of death has been widely studied internationally in cancer [13-15], only one Spanish study has assessed factors associated with place of death from COPD [16], and none for IPD, despite the greater prevalence of respiratory conditions and the imminent global epidemic [3]. Understanding which factors affect place of death is vital for service planning and care improvement, especially given population ageing, rising chronic diseases worldwide and the high costs of hospital admissions [17]. Information to reduce hospitalisations is needed internationally both to meet patient preferences and to ease healthcare costs [18-21].

Therefore, we aimed to compare the trends and factors associated with place of death in people with two common progressive respiratory diseases. We sought to determine whether hospital deaths for individuals dying from COPD or IPD fell after the Strategy was introduced, and after roll out was intensified. To aid future interventions, we also evaluated which factors affected place of death, and whether these were similar across COPD and IPD.

\section{Methods \\ Study design}

Population-based observational study (as per STROBE and RECORD [22] guidelines, Additional file 1) as part of our study of Geographical and Temporal Variations in Place of Death in England (GUIDE_Care) [23].

\section{Data sources}

The Office for National Statistics death registrations in England, which detail decedents' age, sex, marital status, usual residence, place and year of death, and, based on the clinician's death certificate, the underlying and contributing causes of death using the International Classification of Diseases Tenth Revision (ICD-10), employed since 2001.

Office for National Statistics death registration records were linked with area level indices of multiple deprivation (IMD) 2010 [24]. The IMD 2010 is a composite measure of deprivation, providing a weighted average of seven domains: income, employment, health and disability, education, skills and training, living environment and crime, and barriers to housing and services. These are based on the Lower Super Output Area (LSOA) of the decedents' usual residence. There are 32,482 LSOAs in England, with each area having a minimum of 1000 residents and an average of 1500 . LSOAs were grouped into quintiles based on their IMD scores $[13,24,25]$.

\section{Study population}

All deaths between 2001 and 2014 (inclusive) with COPD or IPD as an underlying cause of death (ICD-10 codes: J40-J44, J47 (COPD); J84 (Interstitial pulmonary disease, encompassing all progressive fibrotic interstitial lung diseases including idiopathic pulmonary fibrosis and idiopathic interstitial pneumonia)) were extracted.

\section{Variables}

The main outcome was place of death grouped into six categories: hospital, home, hospice (an inpatient specialist palliative care unit, freestanding or clearly specified within a hospital, 75\% are voluntary, 25\% NHS managed), nursing home, care home or residential home, and elsewhere [13].

Explanatory variables were age at death $(\leq 54,55-64$, $65-74,75-84,85+)$, sex (men, women), year of death (grouped into 2001-2004 (pre-Strategy), 2005-2008 (Strategy first phase, which included the implementation 
of the NICE Guidance and first phase of the EoLC Programme and Strategy), and 2009-2014 (Strategy intensification)), marital status (married, widowed, divorced, single, not stated/unknown), number of co-morbidities assessed from contributory cause(s) of death $(0,1,2,3,4$ + ), type of settlement (rural, urban), socioeconomic status (as measured by IMD of area of residence), and region (defined by Clinical Senate, 2013). We analysed age as an ordered five-category rather than a continuous variable to aid interpretation and comparison with other studies; category boundaries were chosen based on the data distribution [26-28].

\section{Statistical analysis}

We plotted the time trend of age- and sex-standardised proportion of deaths in hospital for COPD and IPD. Proportions were standardised using the 2010-2015 mortality structure for more developed countries from the United Nations standard population [29].

We used Modified Poisson Regression to evaluate the relationship between place of death and potential explanatory variables (selected from those available, according to existing literature and univariable analysis results), including age, sex, marital status, co-morbidity, year of death, IMD, rural/urban indicator and region of the usual residential address (Table 2). The dependent variable was binary $(1=$ hospital, $0=$ non-hospital). We focused on hospital death as this was most common and reducing it was a target of the Strategy. The strength of association was measured using proportion ratios (PRs). Two separate models were constructed for COPD and IPD. The Modified Poisson regression was chosen over the binomial model as the latter failed to converge in IPD [30]. Sensitivity analysis entered year of death as a continuous rather than categorical variable.

All analyses were performed using the SAS 9.4 (SAS Institute, Cary, NC, USA).

\section{Results}

Over the 14 years, 334,520 people died from COPD and 45,712 from IPD (Table 1), representing 5.3\% and 0.7\% of the total 6,368,760 non-accidental deaths during the period. Annual deaths from COPD increased slightly from 23,303 (2001-2004) to 24,717 (2009-2014), representing a yearly increase of $0.9 \%$. The annual number of IPD deaths, although much smaller, almost doubled from 2403 (2001-2004) to 4091 (2009-2014); representing a yearly increase of $9.2 \%$. Across both conditions, more than $65 \%$ of deaths occurred among people aged over 75 years.

Hospital was the most common place of death $(67.3 \%$ for COPD, 70.1\% IPD), followed by home (19.9\% COPD, 19.1\% IPD). Deaths within hospices accounted for just $0.9 \%$ of COPD and $2.9 \%$ of IPD cases (Table 1 ).
The pattern of higher proportions of hospital deaths in IPD was consistent over the years, even when standardised by age and sex. For both groups, the proportion of hospital deaths peaked between 2003 and 2005 (Fig. 1). The proportion of age- and sex-standardised deaths in hospital fell slightly between 2005 and 2014 for people with COPD (from 67\% to 61\%) and IPD (from 71 to $68 \%$ ).

In multivariable analysis (Table 2), hospital deaths reduced significantly over time in both COPD and IPD, with a fall occurring after 2005. Female sex was independently associated with higher hospital deaths in COPD (PR 1.04) but lower in IPD (PR 0.97). In COPD, there was a U-shaped relationship regarding age, with those aged 65-74 years having the highest hospital deaths (PR 1.12); whereas in IPD, increased age was independently associated with fewer hospital deaths (PR 0.81 ). Being married increased the chance of dying in hospital for COPD but not for IPD (Table 2).

Having co-morbidities and living in deprived areas independently increased the chance of dying in hospital, with larger effects for IPD (PRs 1.01-1.55) than COPD (PRs 1.01-1.39) and a "dose-response" relationship (Fig. 2). Living in rural areas as opposed to cities reduced the chances of hospital death (PRs 0.94-0.95). When plotted over the period (Fig. 2), after 2005 hospital deaths fell chiefly for people with no co-morbidities. Hospital deaths did not fall for people with two or more co-morbidities in COPD, or with any co-morbidity in IPD. For deprivation and urban areas, the dose-response relationship appeared to stay constant over time (Fig. 2).

Significant variations by region were observed for both COPD and IPD. For COPD and IPD groups, "London" had the highest hospital deaths, and the "South West" and "South East Coast" regions had lower hospital deaths than most other regions. Sensitivity analysis, with year of death as a continuous variable, produced similar results (Table 3).

\section{Discussion}

In this large population-based study assessing place of death in respiratory disease over 14 years, we found hospital was the most common place of death, and remained constantly higher for people with IPD $(67.5-74.7 \%$, standardised by age and sex) than COPD (61.3-67.4\%). During the period following the introduction of the NICE Guidance on Supportive and Palliative Care, and the introduction and intensification of the EoLC Strategy, hospital deaths fell slightly, by $6 \%$ for people with COPD and $3 \%$ for IPD. In regression analysis, the change after 2005 was significant for both COPD and IPD.

Our design is observational; therefore, as in other population studies, we cannot infer causality. However, 
Table 1 Sociodemographic and clinical characteristics (count, \%) of patients who died from chronic obstructive pulmonary disease (COPD) and interstitial pulmonary disease (IPD), England 2001-2014

\begin{tabular}{|c|c|c|c|}
\hline Variable & Value & COPD $N=334,520$ & IPD $N=45,712$ \\
\hline \multirow[t]{2}{*}{ Age in years } & Mean (SD) & $78.2(9.7)$ & $77.0(10.5)$ \\
\hline & Min-max & $0-108$ & $0-105$ \\
\hline \multirow[t]{5}{*}{ Age group } & $0-54$ & $5593(1.7)$ & $1284(2.8)$ \\
\hline & $55-64$ & $25,283(7.6)$ & $3503(7.7)$ \\
\hline & $65-74$ & $73,095(21.9)$ & $11,180(24.5)$ \\
\hline & $75-84$ & $139,030(41.6)$ & $18,893(41.3)$ \\
\hline & $85+$ & $91,519(27.4)$ & $10,852(23.7)$ \\
\hline \multirow[t]{2}{*}{ Sex } & Male & $175,226(52.4)$ & $28,231(61.8)$ \\
\hline & Female & $159,294(47.6)$ & $17,481(38.2)$ \\
\hline \multirow[t]{5}{*}{ Marital status } & Married & $123,808(37.0)$ & $24,342(53.3)$ \\
\hline & Widowed & $146,706(43.9)$ & $15,280(33.4)$ \\
\hline & Divorced & $36,137(10.8)$ & $3129(6.8)$ \\
\hline & Single & $25,240(7.5)$ & $2651(5.8)$ \\
\hline & Not stated/unknown & $2629(0.8)$ & $310(0.7)$ \\
\hline \multirow{5}{*}{$\begin{array}{l}\text { Number of contributing causes } \\
\text { of death (co-morbidities) }\end{array}$} & 0 & $42,769(12.8)$ & $9547(20.9)$ \\
\hline & 1 & $117,532(35.1)$ & $15,718(34.4)$ \\
\hline & 2 & $94,070(28.1)$ & $11,166(24.4)$ \\
\hline & 3 & $47,641(14.2)$ & $5496(12.0)$ \\
\hline & $4+$ & $32,508(9.7)$ & $3785(8.3)$ \\
\hline \multirow[t]{2}{*}{ Settlement } & Urban & $281,013(84.0)$ & $36,938(80.8)$ \\
\hline & Rural & $53,507(16.0)$ & $8774(19.2)$ \\
\hline \multirow[t]{5}{*}{ Indices of Multiple Deprivation } & 1 - Most deprived & $93,671(28.0)$ & $8632(18.9)$ \\
\hline & 2 & $76,635(22.9)$ & $8769(19.2)$ \\
\hline & 3 & $65,336(19.5)$ & $9698(21.2)$ \\
\hline & 4 & $55,901(16.7)$ & $9783(21.4)$ \\
\hline & 5 - Least deprived & $42,969(12.8)$ & $8829(19.3)$ \\
\hline \multirow[t]{12}{*}{ Clinical senate (i.e. region) } & Cheshire \& Merseyside & $20,004(6.0)$ & $2707(5.9)$ \\
\hline & East Midlands & $28,848(8.6)$ & $4325(9.5)$ \\
\hline & East of England & $33,243(9.9)$ & $4693(10.3)$ \\
\hline & $\begin{array}{l}\text { Greater Manchester, Lancashire } \\
\text { and south Cumbria }\end{array}$ & $33,367(10.0)$ & $4273(9.3)$ \\
\hline & London & $36,184(10.8)$ & $4091(8.9)$ \\
\hline & $\begin{array}{l}\text { North East, north Cumbria, and the } \\
\text { Hambleton \& Richmondshire districts } \\
\text { of North Yorkshire }\end{array}$ & $26,546(7.9)$ & $3185(7.0)$ \\
\hline & South East Coast & $27,489(8.2)$ & $3803(8.3)$ \\
\hline & South West & $28,042(8.4)$ & $4270(9.3)$ \\
\hline & Thames Valley & $9265(2.8)$ & $1378(3.0)$ \\
\hline & Wessex & $15,930(4.8)$ & $2571(5.6)$ \\
\hline & West Midlands & $36,088(10.8)$ & $5473(12.0)$ \\
\hline & Yorkshire \& The Humber & $39,514(11.8)$ & $4943(10.8)$ \\
\hline \multirow[t]{3}{*}{ Year of death (average/year) } & $2001-2004$ & 93,212 (23,303/year) & 9612 (2403/year) \\
\hline & $2005-2008$ & 93,008 (23,252/year) & 11,557 (2889/year) \\
\hline & 2009-2014 & 148,300 (24,717/year) & 24,543 (4091/year) \\
\hline
\end{tabular}


Table 1 Sociodemographic and clinical characteristics (count, \%) of patients who died from chronic obstructive pulmonary disease (COPD) and interstitial pulmonary disease (IPD), England 2001-2014 (Continued)

\begin{tabular}{|c|c|c|c|}
\hline \multirow[t]{6}{*}{ Place of death } & Hospital & $225,024(67.3)$ & $32,066(70.1)$ \\
\hline & Home & $66,510(19.9)$ & 8748 (19.1) \\
\hline & Hospice & $2882(0.9)$ & $1330(2.9)$ \\
\hline & Nursing home & $21,142(6.3)$ & $1935(4.2)$ \\
\hline & Care/Residential home & $16,358(4.9)$ & $1318(2.9)$ \\
\hline & Elsewhere & $2604(0.8)$ & $315(0.7)$ \\
\hline
\end{tabular}

Comparison of IPD versus COPD all $P<0.0001$

our findings meet many of the Bradford-Hill and related criteria [31] for providing evidence supporting a causal relationship. There is strength, consistency, specificity and coherence in our findings. We observed a similar but more pronounced and immediate effect in adults who died from cancer - the traditionally best served condition by palliative and end of life care [13]. Conversely, in children and young people with cancer, a patient population rarely accessing palliative and end of life care services, the Strategy made little impact on where people die [32]. There is strong evidence of temporality, with the changes emerging after the Strategy was introduced and increased after it was intensified.

For both conditions, multimorbidity, social deprivation and living in urban areas were associated with dying in hospital, with larger effects for IPD than COPD. We found a "dose-response" effect, with higher deprivation and multimorbidity producing the largest effects on dying in hospital. Increased age and being female were associated with higher hospital deaths in COPD but lower in IPD. In both groups, being single, widowed or divorced, and living in rural or outside London areas were associated with reduced chances of dying in hospital. These data are ecological, and may be subject to the ecological fallacy, whereby the risk-associations apparent for social deprivation, multimorbidity, or other factors may not accurately reflect the true association between individuals within those groups. However, our findings meet the Bradford-Hill criteria of a dose-response relationship. These associations could be examined further in prospective research.

Our findings suggest the EoLC Strategy contributed to tangible impact in reducing hospital deaths for people with respiratory diseases. However, the effects were mainly for people with few or no co-morbidities; people with two or more co-morbidities had no reduction in hospital deaths over the period. Most healthcare systems are dominantly established for people with individual diseases [33, 34]. Many different specialists can become involved during multimorbidity. This can be duplicative, burdensome and unsafe for patients because of poor coordination and integration, with some patients inversely receiving less care $[33,35,36]$. Another reason might be that the more medical specialists are involved, the higher

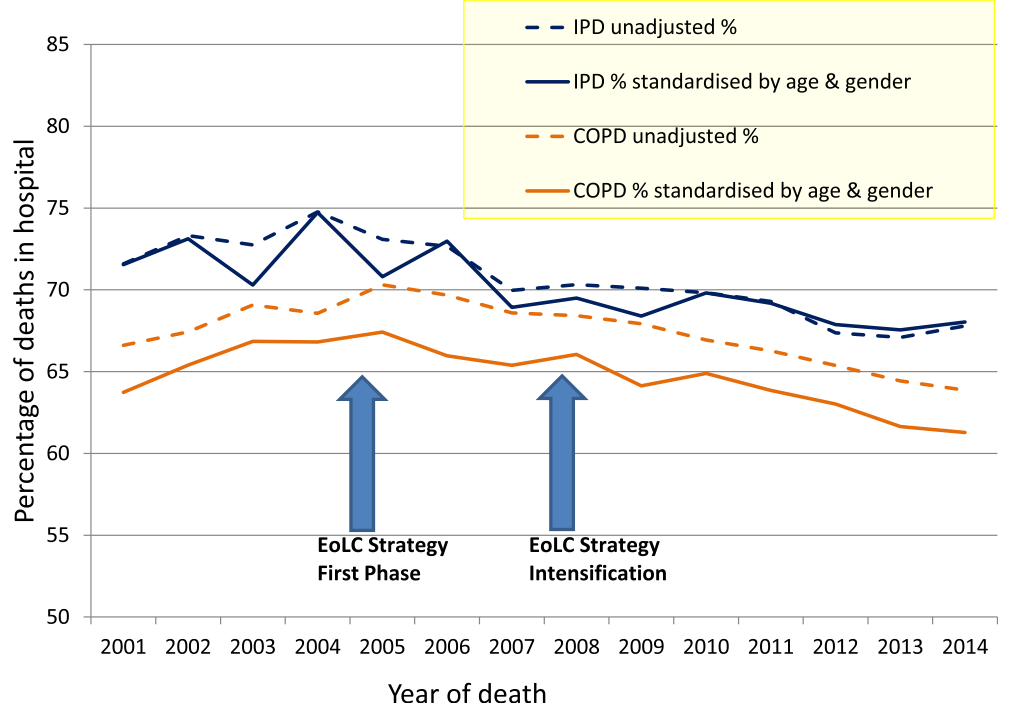

Fig. 1 Time trends of percentage of deaths in hospital by year for chronic obstructive pulmonary disease (COPD) and interstitial pulmonary disease (IPD). Unadjusted and standardised by age and sex against the United Nations mortality standard population 
Table 2 Factors associated with place of death ${ }^{a}$ (hospital versus non-hospital) in patients who died from chronic obstructive pulmonary disease ((COPD) and interstitial pulmonary disease (IPD), England 2001-2014

\begin{tabular}{|c|c|c|c|c|c|}
\hline \multirow[t]{3}{*}{ Variable (Ref) } & \multirow[t]{3}{*}{ Value } & \multicolumn{4}{|c|}{$\underline{\text { Underlying cause of death }}$} \\
\hline & & \multicolumn{2}{|l|}{ COPD } & \multicolumn{2}{|l|}{$\underline{\mathrm{IPD}}$} \\
\hline & & $\begin{array}{l}\text { Unadjusted } \\
\text { PR (95\% Cl) }\end{array}$ & Adjusted PR & Unadjusted PR & Adjusted PR \\
\hline \multirow[t]{4}{*}{ Age $(\leq 54)$} & $55-64$ & $1.07(1.05-1.10)$ & $1.07(1.04-1.09)$ & $0.95(0.92-0.98)$ & $0.95(0.92-0.98)$ \\
\hline & $65-74$ & $1.13(1.11-1.16)$ & $1.12(1.10-1.14)$ & $0.89(0.87-0.92)$ & $0.90(0.88-0.93)$ \\
\hline & $75-84$ & $1.13(1.11-1.16)$ & $1.11(1.08-1.13)$ & $0.85(0.83-0.87)$ & $0.85(0.83-0.88)$ \\
\hline & $85+$ & $1.04(1.02-1.06)$ & $1.02(1.00-1.04)$ & $0.82(0.79-0.84)$ & $0.81(0.79-0.84)$ \\
\hline Sex (Male) & Female & $1.02(1.01-1.02)$ & $1.04(1.03-1.04)$ & $0.96(0.95-0.97)$ & $0.97(0.95-0.98)$ \\
\hline \multirow[t]{4}{*}{ Marital status (Married) } & Divorced & $0.93(0.92-0.93)$ & $0.92(0.91-0.93)$ & $1.02(0.99-1.04)$ & $0.99(0.96-1.01)$ \\
\hline & Single & $0.89(0.88-0.90)$ & $0.89(0.88-0.90)$ & $1.02(1.00-1.05)$ & $0.98(0.96-1.00)$ \\
\hline & Widowed & $0.95(0.94-0.95)$ & $0.95(0.94-0.95)$ & $0.98(0.97-0.99)$ & $1.01(0.99-1.02)$ \\
\hline & NS/unknown & $0.84(0.82-0.87)$ & $0.83(0.81-0.86)$ & $0.96(0.88-1.03)$ & $0.87(0.80-0.94)$ \\
\hline \multirow[t]{2}{*}{ Year of death (2001-2004) } & $2005-2008$ & $1.02(1.01-1.03)$ & $1.01(1.00-1.02)$ & $0.98(0.96-0.99)$ & $0.97(0.95-0.99)$ \\
\hline & $2009-2014$ & $0.97(0.96-0.97)$ & $0.94(0.94-0.95)$ & $0.93(0.92-0.95)$ & $0.92(0.90-0.93)$ \\
\hline \multirow{4}{*}{$\begin{array}{l}\text { No. contributing } \\
\text { causes of death } \\
\text { (co-morbidities) (0) }\end{array}$} & 1 & $1.04(1.03-1.05)$ & $1.06(1.05-1.07)$ & $1.26(1.23-1.28)$ & $1.26(1.24-1.29)$ \\
\hline & 2 & $1.08(1.07-1.09)$ & $1.10(1.09-1.11)$ & $1.32(1.30-1.35)$ & $1.33(1.31-1.36)$ \\
\hline & 3 & $1.20(1.19-1.21)$ & $1.23(1.22-1.24)$ & $1.41(1.38-1.44)$ & $1.42(1.39-1.46)$ \\
\hline & $4+$ & $1.35(1.34-1.36)$ & $1.39(1.37-1.40)$ & $1.52(1.49-1.56)$ & $1.55(1.52-1.59)$ \\
\hline \multirow{4}{*}{$\begin{array}{l}\text { Indices of Multiple } \\
\text { Deprivation } 5 \\
\text { (Least deprived) }\end{array}$} & 1 (Most deprived) & $1.06(1.06-1.07)$ & $1.05(1.04-1.05)$ & $1.15(1.13-1.17)$ & $1.08(1.05-1.10)$ \\
\hline & 2 & $1.05(1.04-1.06)$ & $1.04(1.03-1.05)$ & $1.10(1.08-1.12)$ & $1.05(1.03-1.08)$ \\
\hline & 3 & $1.03(1.02-1.04)$ & $1.03(1.02-1.04)$ & $1.05(1.03-1.08)$ & $1.03(1.01-1.05)$ \\
\hline & 4 & $1.01(1.00-1.02)$ & $1.01(1.00-1.02)$ & $1.02(1.00-1.04)$ & $1.01(0.99-1.03)$ \\
\hline Rural/urban (Urban) & Rural & $0.93(0.92-0.94)$ & $0.95(0.94-0.96)$ & $0.90(0.89-0.92)$ & $0.94(0.93-0.96)$ \\
\hline \multirow[t]{11}{*}{ Region (London) } & Cheshire \& Merseyside & $0.97(0.96-0.98)$ & $0.96(0.95-0.97)$ & $0.92(0.89-0.94)$ & $0.92(0.90-0.95)$ \\
\hline & East Midlands & $0.95(0.94-0.96)$ & $0.95(0.94-0.96)$ & $0.91(0.88-0.93)$ & $0.94(0.91-0.96)$ \\
\hline & East of England & $0.96(0.95-0.97)$ & $0.96(0.96-0.97)$ & $0.90(0.87-0.92)$ & $0.93(0.91-0.96)$ \\
\hline & $\begin{array}{l}\text { Greater Manchester, Lancashire } \\
\text { and south Cumbria }\end{array}$ & $0.98(0.97-0.99)$ & $0.97(0.97-0.98)$ & $0.97(0.95-0.99)$ & $0.98(0.96-1.01)$ \\
\hline & $\begin{array}{l}\text { North East, north Cumbria, } \\
\text { and the Hambleton \& } \\
\text { Richmondshire districts of } \\
\text { North Yorkshire }\end{array}$ & $0.96(0.95-0.97)$ & $0.94(0.93-0.95)$ & $0.95(0.92-0.97)$ & $0.96(0.94-0.99)$ \\
\hline & South East Coast & $0.92(0.91-0.93)$ & $0.94(0.93-0.95)$ & $0.85(0.82-0.87)$ & $0.89(0.86-0.91)$ \\
\hline & South West & $0.89(0.88-0.90)$ & $0.91(0.90-0.92)$ & $0.84(0.82-0.87)$ & $0.89(0.86-0.91)$ \\
\hline & Thames Valley & $0.94(0.92-0.95)$ & $0.96(0.94-0.98)$ & $0.87(0.84-0.91)$ & $0.93(0.89-0.97)$ \\
\hline & Wessex & $0.93(0.92-0.95)$ & $0.94(0.93-0.95)$ & $0.90(0.88-0.93)$ & $0.95(0.92-0.98)$ \\
\hline & West Midlands & $0.98(0.97-0.99)$ & $0.96(0.95-0.97)$ & $0.94(0.92-0.97)$ & $0.95(0.93-0.98)$ \\
\hline & Yorkshire \& The Humber & $0.93(0.92-0.94)$ & $0.92(0.91-0.93)$ & $0.91(0.89-0.94)$ & $0.93(0.91-0.95)$ \\
\hline
\end{tabular}

${ }^{a}$ The association is measured by proportion ratios (PRs) and 95\% confidence intervals. PR $>1$ indicates a higher probability of hospital death, $<1$ lower chance of hospital death, $P R=1$ indicates no association. The adjusted PRs were derived from modified Poisson regression model, adjusting for the listed variables

the chance of the family doctor or general practitioner (GP) having a minor role in the care of the patient, thus being less often aware of the progressive stage of the diseases. Supporting patients with multimorbidity needs knowledge and expertise that a GP may not always have, which may be a reason for why GPs may refer to hospital during crises. These factors could increase hospital admissions and length of stay.

Multimorbidity is increasing globally [37, 38]. In the UK, the number of people with three or more long-term conditions is predicted to rise from 1.9 million in 2008 to 2.9 million in 2018 , requiring a major increase in 
COPD

IPD

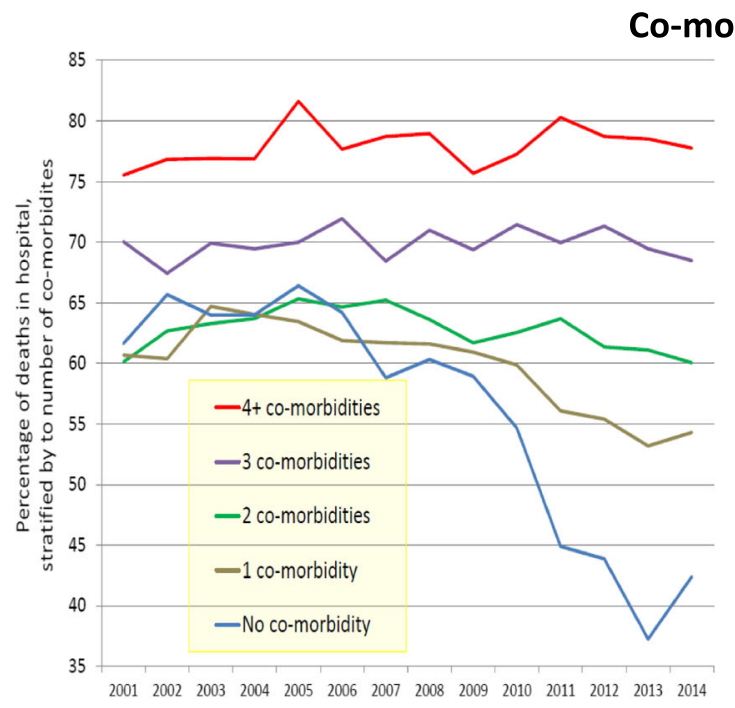

\section{idities}

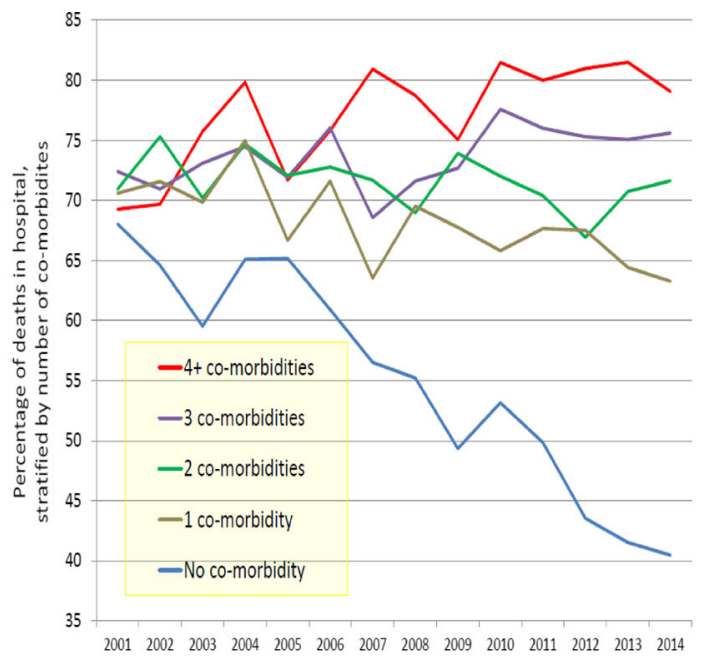

Year of death for people with COPD

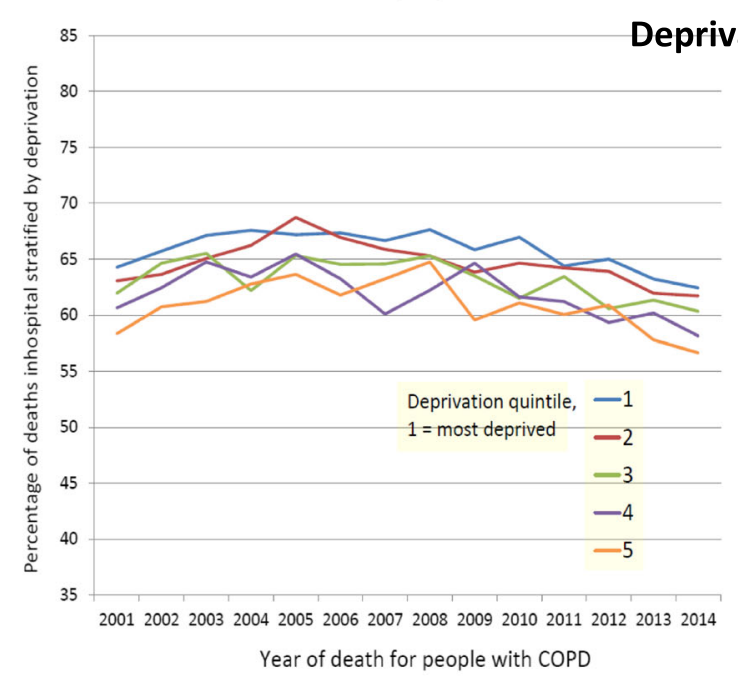

Year of death for people with IPD
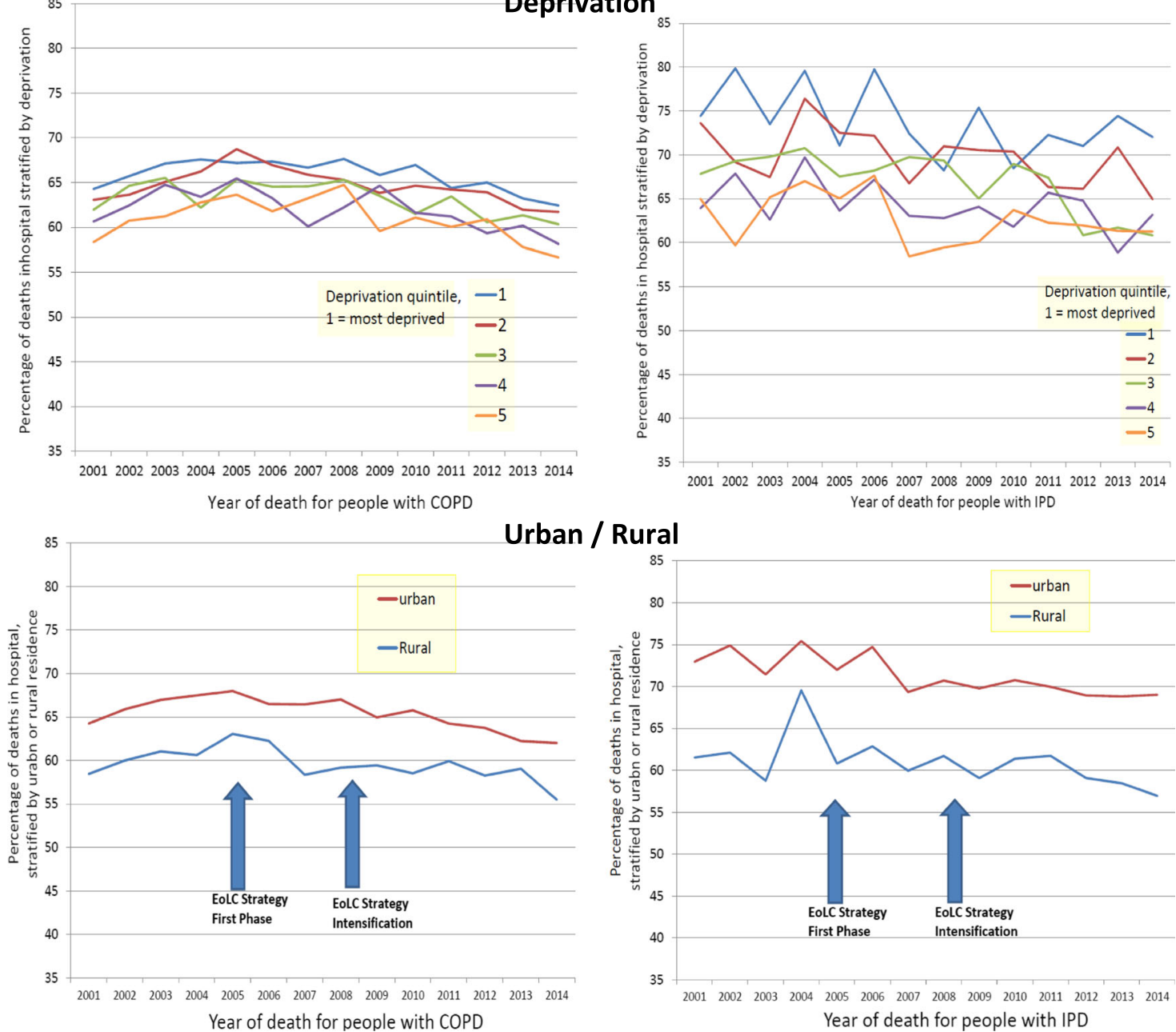

Fig. 2 Time trends of percentage of deaths in hospital for COPD and IPD stratified according to number of co-morbidities, deprivation score and living in urban or rural areas. Percentages are age and gender standardised against the United Nations mortality standard population 
Table 3 Sensitivity analysis. Factors associated with place of death ${ }^{\mathrm{a}}$ (hospital versus non-hospital) in patients who died from chronic obstructive pulmonary disease (COPD) and interstitial pulmonary diseases (IPD), England 2001-2014, using year of death as a continuous variable

\begin{tabular}{|c|c|c|c|c|c|}
\hline \multirow[t]{3}{*}{ Variable (Ref) } & \multirow[t]{3}{*}{ Value } & \multicolumn{4}{|c|}{ Underlying Cause of Death } \\
\hline & & \multicolumn{2}{|l|}{ COPD } & \multicolumn{2}{|l|}{ IPD } \\
\hline & & Unadjusted PR (95\% Cl) & Adjusted PR & Unadjusted PR & Adjusted PR \\
\hline \multirow[t]{4}{*}{ Age $(\leq 54)$} & $55-64$ & $1.07(1.05-1.10)$ & $1.07(1.05-1.09)$ & $0.95(0.92-0.98)$ & $0.95(0.92-0.98)$ \\
\hline & $65-74$ & $1.13(1.11-1.16)$ & $1.12(1.10-1.14)$ & $0.89(0.87-0.92)$ & $0.90(0.88-0.93)$ \\
\hline & $75-84$ & $1.13(1.11-1.16)$ & $1.11(1.09-1.13)$ & $0.85(0.83-0.87)$ & $0.85(0.83-0.88)$ \\
\hline & $85+$ & $1.04(1.02-1.06)$ & $1.02(1.00-1.04)$ & $0.82(0.79-0.84)$ & $0.82(0.79-0.84)$ \\
\hline Sex (Male) & Female & $1.02(1.01-1.02)$ & $1.04(1.03-1.05)$ & $0.96(0.95-0.97)$ & $0.97(0.95-0.98)$ \\
\hline \multirow[t]{4}{*}{ Marital status (Married) } & Divorced & $0.93(0.92-0.93)$ & $0.92(0.92-0.93)$ & $1.02(0.99-1.04)$ & $0.99(0.96-1.01)$ \\
\hline & Single & $0.89(0.88-0.90)$ & $0.89(0.88-0.90)$ & $1.02(1.00-1.05)$ & $0.98(0.96-1.01)$ \\
\hline & Widowed & $0.95(0.94-0.95)$ & $0.95(0.94-0.95)$ & $0.98(0.97-0.99)$ & $1.01(0.99-1.02)$ \\
\hline & NS/unknown & $0.84(0.82-0.87)$ & $0.83(0.81-0.86)$ & $0.96(0.88-1.03)$ & $0.87(0.80-0.94)$ \\
\hline Year of death & - & $0.995(0.995-0.996)$ & $0.992(0.992-0.993)$ & $0.993(0.991-0.994)$ & $0.991(0.989-0.992)$ \\
\hline \multirow{4}{*}{$\begin{array}{l}\text { No. contributing } \\
\text { Causes of Death } \\
\text { (co-morbidities) (0) }\end{array}$} & 1 & $1.04(1.03-1.05)$ & $1.06(1.05-1.07)$ & $1.26(1.23-1.28)$ & $1.26(1.23-1.29)$ \\
\hline & 2 & $1.08(1.07-1.09)$ & $1.10(1.09-1.11)$ & $1.32(1.30-1.35)$ & $1.33(1.31-1.36)$ \\
\hline & 3 & $1.20(1.19-1.21)$ & $1.23(1.22-1.24)$ & $1.41(1.38-1.44)$ & $1.42(1.39-1.46)$ \\
\hline & $4+$ & $1.35(1.34-1.36)$ & $1.39(1.38-1.40)$ & $1.52(1.49-1.56)$ & $1.55(1.52-1.59)$ \\
\hline \multirow{4}{*}{$\begin{array}{l}\text { Indices of Multiple } \\
\text { Deprivation } 5 \\
\text { (Least deprived) }\end{array}$} & 1 (Most deprived) & $1.06(1.05-1.07)$ & $1.05(1.04-1.06)$ & $1.15(1.13-1.17)$ & $1.08(1.05-1.10)$ \\
\hline & 2 & $1.05(1.04-1.06)$ & $1.04(1.03-1.05)$ & $1.10(1.08-1.12)$ & $1.05(1.03-1.08)$ \\
\hline & 3 & $1.03(1.02-1.04)$ & $1.03(1.02-1.04)$ & $1.05(1.03-1.08)$ & $1.03(1.01-1.05)$ \\
\hline & 4 & $1.01(1.00-1.02)$ & $1.01(1.00-1.02)$ & $1.02(1.00-1.04)$ & $1.01(0.99-1.03)$ \\
\hline Rural/urban (Urban) & Rural & $0.93(0.92-0.94)$ & $0.95(0.94-0.96)$ & $0.90(0.89-0.92)$ & $0.94(0.93-0.96)$ \\
\hline \multirow[t]{11}{*}{ Region (London) } & Cheshire \& Merseyside & $0.97(0.96-0.98)$ & $0.96(0.95-0.97)$ & $0.92(0.89-0.94)$ & $0.92(0.90-0.95)$ \\
\hline & East Midlands & $0.95(0.94-0.96)$ & $0.95(0.94-0.96)$ & $0.91(0.88-0.93)$ & $0.94(0.91-0.96)$ \\
\hline & East of England & $0.96(0.95-0.97)$ & $0.97(0.96-0.97)$ & $0.90(0.87-0.92)$ & $0.93(0.91-0.96)$ \\
\hline & $\begin{array}{l}\text { Greater Manchester, Lancashire } \\
\text { and south Cumbria }\end{array}$ & $0.98(0.97-0.99)$ & $0.97(0.97-0.98)$ & $0.97(0.95-0.99)$ & $0.98(0.96-1.01)$ \\
\hline & $\begin{array}{l}\text { North East, north Cumbria, and } \\
\text { the Hambleton \& Richmondshire } \\
\text { districts of North Yorkshire }\end{array}$ & $0.96(0.95-0.97)$ & $0.94(0.93-0.95)$ & $0.95(0.92-0.97)$ & $0.96(0.94-0.99)$ \\
\hline & South East Coast & $0.92(0.91-0.93)$ & $0.94(0.93-0.95)$ & $0.85(0.82-0.87)$ & $0.89(0.86-0.91)$ \\
\hline & South West & $0.89(0.88-0.90)$ & $0.91(0.90-0.92)$ & $0.84(0.82-0.87)$ & $0.89(0.86-0.91)$ \\
\hline & Thames Valley & $0.94(0.92-0.95)$ & $0.96(0.94-0.98)$ & $0.87(0.84-0.91)$ & $0.93(0.89-0.97)$ \\
\hline & Wessex & $0.93(0.92-0.95)$ & $0.94(0.93-0.95)$ & $0.90(0.88-0.93)$ & $0.95(0.92-0.98)$ \\
\hline & West Midlands & $0.98(0.97-0.99)$ & $0.96(0.95-0.97)$ & $0.94(0.92-0.97)$ & $0.95(0.93-0.98)$ \\
\hline & Yorkshire \& The Humber & $0.93(0.92-0.94)$ & $0.92(0.91-0.93)$ & $0.91(0.89-0.94)$ & $0.93(0.91-0.95)$ \\
\hline
\end{tabular}

${ }^{a}$ The association is measured by proportion ratios(PRs) and $95 \%$ confidence intervals. PR $>1$ indicates a higher probability of hospital death, $<1$ lower chance of hospital death, $\mathrm{PR}=1$ indicates no association. The adjusted PRs were derived from modified Poisson regression model, adjusting for the listed variables

healthcare expenditure [39]. It was particularly concerning that, in our data, there was no fall in hospital deaths for people with multimorbidity, and the disparity widened over time. Therefore, it is essential that future strategies for end of life and palliative care directly address the issue of multimorbidity, and this may require different approaches.
Median survival for people with IPD is poor, at between 2 and 5 years from diagnosis [40]. Prognosis in COPD is better, though around one third die within 3 years following diagnosis [41]. However, it is difficult to prognosticate, as many people have frequent exacerbations of their disease and encounter life-threatening events before death occurs. Prognostication, especially 
during the last year of life, is problematic when patients have multimorbidity. Patients with COPD and IPD often suffer refractory breathlessness, which can result in panic and distress [42]. Breathlessness is often unpredictable and episodic [5, 43], with multiple other symptoms that can result in accident and emergency attendance [44]. Managing refractory breathlessness and issues in multimorbidity is therefore more complex and time consuming than for single conditions, especially responding to the needs for 'joined-up' co-ordination, communication and symptom management $[35,36]$. Organising some specific treatments, such as non-invasive ventilation in COPD, also may take time in the community.

Taken together, these findings suggest that earlier palliative care is needed, with an integrated short-term assessment and review. Two challenges exist regarding access to end of life or palliative care for a patient with organ failure. Firstly, when and how to trigger care? As prognostication is difficult, professionals can have 'prognostic paralysis', and may postpone discussions with patients about the future. Secondly, patients may not realise or acknowledge that they have a life-limiting disease. This is often not clearly communicated by the healthcare professionals, which implies that preferred place of death is not discussed [45]. Early palliative care could be triggered by multimorbidity and complexity in terms of symptoms and needs rather than waiting until the end of life is apparent or acknowledged. Evidence supports such services; strong evidence supports early integration in cancer $[46,47]$ and evidence is emerging in respiratory and mixed conditions for integrated breathlessness support services [48, 49], hospital to home [50] and multiprofessional teams [51]. Perhaps multimorbidity should be a specific focus for palliative care. A recent study found the cost-savings of palliative care were largest among patients with multimorbidity, costs were $22 \%$ lower than standard care for patients with a co-morbidity score of $2-3$ and with $32 \%$ lower for those with a score of 4 or higher [52]. There may be a role for tools to understand and elicit discussions earlier in care, including in Intensive Care Units [53, 54], and for palliative care units in the acute hospital where noninvasive ventilation can be provided. Exactly how integration should occur needs to be tailored to the characteristics of the healthcare system and the local resources but evidence suggests that identification based on clinical characteristics is more reliable than relying on clinicians to remember to make referrals [46]. The factors identified in this study, along with the symptom of breathlessness, could be applied to trigger more integrated palliative support, with models such as a breathlessness support service [49]. Hospices, which in the UK provide inpatient specialist palliative care, remained a rare place of death, yet these may be appropriate places outside of hospitals to care for more complex patients with multimorbidity.

Our findings support other research that found deprivation is associated with higher hospital and fewer home deaths in cancer and COPD $[15,55,56]$, and studies in COPD suggesting that deprivation and co-morbidity are associated with hospital admission and readmission for acute exacerbation $[17,57,58]$. We could find no literature on deprivation in IPD; ours appears to be the first study to consider this group. It would seem plausible that more hospital admissions may lead to greater chances of dying in hospital. McAllister et al.'s [55] study in Scotland found that winter and socioeconomic deprivation-related factors appear to act synergistically, increasing the rate of COPD admissions to hospital more among deprived people and in winter. The results suggest there may be a role for targeting initiatives in deprived areas and in winter. Interestingly, we found both diseases were still increasing in frequency as a cause of death over the period and for COPD this appears to run contrary to other European trends [59].

Factors such as being widowed or divorced making hospital deaths less likely in COPD are surprising; this is independent of age and may suggest the presence of family members increased the chance of patients being admitted to hospitals. Qualitative work has identified gaps in information and support for patients, families and professionals, who are often invisible to services [60]. The findings highlight more work is needed to support patients and family members at home, who often struggle in knowing what to do when breathlessness escalates [61].

For COPD, our findings of age and sex run contrary to those of a study of 4983 decedents in Andalusia, Spain [16], where older age and female sex were associated with home death. However, the Andalusia study controlled for a smaller number of potential confounders, e.g. deprivation and co-morbidities were not assessed, whereas both were important in our study. It also considered only one year, 2009, and focussed on factors associated with deaths at home versus elsewhere rather than with hospital versus elsewhere. In accordance with our results, the Andalusia study found rural residents were more likely to die at home.

Our study was limited by the nature of data available. We do not have information to address the appropriateness of the place of end of life care and the quality of the care provided. COPD and IPD can be characterised by a trajectory of a prolonged phase of recurrent exacerbations with recovery. Patients and their families are often acutely distressed during an exacerbation. Standard medical treatments are often appropriate in correcting reversible processes, and also in providing symptom relief in these circumstances. Thus, palliative and end of 
life care strategies may well need to be different for these patients than for cancer patients. Approximately $70 \%$ of the patients died in hospital, with patients admitted to hospital rather than remaining at home. Primary care and hospital teams may have thought that admission was the best option [61]. Many services have now moved on from the limitations of applying the generic EoLC strategy to COPD and IPD patients, to a model of care whereby standard medical and palliative care are delivered in parallel, in an integrated way, particularly in diseases where the patient has a good prospect of recovery from an acute exacerbation.

Other research indicates that people with COPD and IPD often miss out on the best care in advanced stages of illness, in the community, in hospital, and from palliative care $[8,62,63]$. Our finding of high hospital use may be a result of lower quality care and forward planning, driving emergency admissions [61, 63, 64]. There is little research on the preferences for place of care and death of people with respiratory disease, but there is no data to indicate that their preferences are especially different from other groups [14]. It is possible that COPD and IPD were misclassified as a cause of death, but as we focussed on recent years, this effect is likely to be minimised. The increase in mortality from IPD has been partly linked to better identification of the disease [2, 4]. The apparent growth in IPD in our study may also be as a result of this trend. It is also possible that classification of IPD and COPD as a cause of death is influenced by setting, and other conditions, such as pneumonia, are more commonly recorded in community settings, thus underestimating COPD and IPD deaths in these settings. However, these limitations would be unlikely to affect the trends over time or the associated factors. The only concern would be if the Strategy helped to identify people with COPD and IPD earlier, which lead to increased community identification and recording as a cause of death. If this occurred, the effect of the Strategy found here would be over-estimated. Multimorbidity is usually defined as the presence of two or more chronic diseases within an individual. We used the reported contributing causes of death to determine the number of co-morbidities. It may have been that only more major co-morbidities were recorded and therefore the number of co-morbidities may be underestimated. However, the presence of the clear trend shows the need to focus more clearly in the future on multimorbidity and its potential role. Our factors and trends point the way to potential interventions to improve care.

\section{Conclusions}

Hospital deaths from COPD and IPD fell by $3-6 \%$ in the 8 years following the introduction of the EoLC strategy; however, those with multimorbidity did not show a fall in hospital deaths. Multimorbidity, deprivation, living in cities, and living in London play a greater role in affecting where people with IPD die than those with COPD. Age and sex affect the chance of hospital death differently for COPD and IPD. Being married rather than single, widowed or divorced made hospital death more likely in COPD, but not in IPD. Thus, the results suggest that the EoLC Strategy may have helped to shift some deaths out of hospital for people with respiratory disease but more integrated approaches of earlier palliative care are needed, targeting those at highest risk, especially with multimorbidity, and in deprived areas and cities. Further initiatives and trials are needed to understand and to improve the quality of care for people both in hospital (where most people are dying) and at home.

\section{Additional file}

Additional file 1: Inclusion of information in paper according to RECORD and STROBE statements that should be reported in observational studies using routinely collected health data. (DOCX $21 \mathrm{~kb}$ )

\section{Abbreviations}

COPD: chronic obstructive pulmonary disease; EoLC: end of life care; GP: general practitioner; GUIDE_Care: Geographical and Temporal Variations in Place of Death in England (1984-2010) Understanding Trends and Associated Factors to Improve End-of-life Care; ICD-10: International Classification of Diseases Tenth Revision; IMD: Index of Multiple Deprivation; IPD: interstitial pulmonary diseases; LSOA: lower super output area; PR: proportion ratios; RECORD: REporting of studies Conducted using Observational Routinely-collected Data; STROBE: STrengthening the Reporting of Observational studies in Epidemiology

\section{Acknowledgements}

Investigators of the GUIDE_Care project: Irene J Higginson (PI), Wei Gao, Julia Verne, Myer Glickman, and Barbara Gomes.

Members of the Project Advisory Group (PAG): Tony Bonser, Shaheen Khan, Jonathan Koffman, Katie Lindsey, Roberta Lovick, Tariq Malik, Carolyn Morris, Andy Pring, Stafford Scholes, Katherine Sleeman.

We thank the Office for National Statistics (ONS) for supplying data; ONS staff Dr Claudia Wells, Vanessa Fearn, and Julie Messer for their advice and support in the preparation of the data for analysis, and Emma Gordon and Julie Messer for critically commenting on data-related issues.

Prof Irene J Higginson is an NIHR Senior Investigator Emeritus.

\section{Funding}

GUIDE_Care was funded by the National Institute for Health Research Health Services and Delivery Research (NIHR HS\&DR) programme (Project number 09/ 2000/58). Additional support came from the Collaboration for Leadership in Applied Health Research and Care (CLAHRC) South London, part of the National Institute for Health Research (NIHR), and a partnership between King's Health Partners, St. George's, University London, and St George's Healthcare NHS Trust and the charity Cicely Saunders International's Breathlessness Programme. The funders had no role in study design, data collection and analysis, decision to publish, or preparation of the manuscript. The views and opinions expressed therein are those of the authors and do not necessarily reflect those of the HS\&DR programme, NHHR, NHS, or the Department of Health.

Availability of data and materials

According to the data agreement we signed with the ONS, we are not allowed to share our data. The access to the data would need special approvals from the ONS. 


\section{Authors' contributions}

$\mathrm{IJH}$ and WG were responsible for the conception and design of the study, and obtained the funding for this paper and take responsibility for the content. CR, MM and SB contributed to the idea of the study. IJH drafted the paper with added contributions from the co-authors. WG and IJH developed the statistical analysis plan. WG conducted the statistical analysis and evaluation. MC suggested further revisions to the analysis. All authors critically revised the report and approved the submitted version.

\section{Competing interests}

The authors declare that they have no competing interests.

\section{Ethics approval and consent to participate}

Following ONS procedures, a Data Access Agreement was signed, with requisites for data management and protection. In addition, as required, all researchers accessing the data $(\mathrm{WG}, \mathrm{IJH})$ were individually assessed and approved by ONS. This study was based on fully anonymised records and therefore no ethical approval was required according to the Information Commissioner's Office guidelines, ONS procedures and those of the King's College London Research Ethics Committee.

\section{Author details}

${ }^{1}$ Cicely Saunders Institute of Palliative Care, Policy \& Rehabilitation, King's College London, Bessemer Road, London SE5 9PJ, UK. ${ }^{2}$ Arcispedale Santa Maria Nuova-IRCCS, Viale Umberto I, 50 - 42123, Reggio Emilia, Italy.

Received: 7 October 2016 Accepted: 23 December 2016

Published online: 01 February 2017

\section{References}

1. World Health Organization. Chronic obstructive pulmonary disease (COPD). Geneva: WHO; 2015. http://www.who.int/mediacentre/factsheets/fs315/en/ Accessed 3 July 2016.

2. Hutchinson JP, McKeever TM, Fogarty AW, Navaratnam V, Hubbard RB. Increasing global mortality from idiopathic pulmonary fibrosis in the twenty-first century. Ann Am Thorac Soc. 2014;11(8):1176-85.

3. Barnes PJ. Chronic obstructive pulmonary disease: effects beyond the lungs. PLoS Med. 2010;7(3), e1000220.

4. Navaratnam V, Fogarty AW, Glendening R, McKeever T, Hubbard RB. The increasing secondary care burden of idiopathic pulmonary fibrosis: hospital admission trends in England from 1998 to 2010. Chest. 2013;143(4):1078-84.

5. Bausewein C, Booth S, Gysels M, Kuhnbach R, Haberland B, Higginson IJ. Understanding breathlessness: cross-sectional comparison of symptom burden and palliative care needs in chronic obstructive pulmonary disease and cancer. J Palliat Med. 2010;13(9):1109-18.

6. Bausewein C, Booth S, Gysels M, Kuhnbach R, Haberland B, Higginson IJ. Individual breathlessness trajectories do not match summary trajectories in advanced cancer and chronic obstructive pulmonary disease: results from a longitudinal study. Palliat Med. 2010;24(8):777-86.

7. Epiphaniou E, Shipman C, Harding R, Mason B, Murray SA, Higginson IJ, Daveson BA. Coordination of end-of-life care for patients with lung cancer and those with advanced COPD: are there transferable lessons? A longitudinal qualitative study. Prim Care Respir J. 2014:23(1):46-51.

8. Bajwah S, Koffman J, Higginson IJ, Ross JR, Wells AU, Birring SS, Riley J. 'I wish I knew more ...' the end-of-life planning and information needs for end-stage fibrotic interstitial lung disease: views of patients, carers and health professionals. BMJ Support Palliat Care. 2013:3(1):84-90.

9. Gomes B, Higginson IJ, Calanzani N, Cohen J, Deliens L, Daveson BA, Bechinger-English D, Bausewein C, Ferreira PL, Toscani F, Menaca A, Gysels M, Ceulemans L, Simon ST, Pasman HR, Albers G, Hall S, Murtagh FE, Haugen DF, Downing J, Koffman J, Pettenati F, Finetti S, Antunes B, Harding R. PRISMA. Preferences for place of death if faced with advanced cancer: a population survey in England, Flanders, Germany, Italy, the Netherlands, Portugal and Spain. Ann Oncol. 2012;23(8):2006-15.

10. National Institute for Clinical Excellence. Improving Supportive and Palliative Care for Adults with Cancer: The Manual. London: National Institute for Clinical Excellence; 2004

11. Seymour J. Looking back, looking forward: the evolution of palliative and end-of-life care in England. Mortality. 2012;17(1):1-17.
12. Department of Health. National End of Life Care Strategy. London: Department of Health; 2008. https:/www.gov.uk/government/uploads/system/uploads/ attachment_data/file/136431/End_of_life_strategy.pdf. Accessed 6 Oct 2016.

13. Gao W, Ho YK, Verne J, Glickman M, Higginson IJ, GUIDE_Care project. Changing patterns in place of cancer death in England: a population-based study. PLoS Med. 2013;10(3):e1001410.

14. Gomes B, Calanzani N, Gysels M, Hall S, Higginson IJ. Heterogeneity and changes in preferences for dying at home: a systematic review. BMC Palliat Care. 2013;12:7.

15. Gomes B, Higginson IJ. Factors influencing death at home in terminally ill patients with cancer: systematic review. BMJ. 2006;332(7540):515-21.

16. Lopez-Campos JL, Ruiz-Ramos M, Mendez C, Garcia-Leon J. Characteristics of subjects who died of chronic obstructive pulmonary disease in Andalusia in 2010 and 2011. J Palliat Med. 2013;16(12):1610-3.

17. Milne RJ, Beasley R. Hospital admissions for chronic obstructive pulmonary disease in New Zealand. N Z Med J. 2015;128(1408):23-35.

18. Henson LA, Gomes B, Koffman J, Daveson BA, Higginson IJ, Gao W, BuildCare. Factors associated with aggressive end of life cancer care. Support Care Cancer. 2016:24(3):1079-89.

19. Gomes B, Calanzani N, Koffman J, Higginson IJ. Is dying in hospital better than home in incurable cancer and what factors influence this? A population-based study. BMC Med. 2015;13:235.

20. Gomes B, Calanzani N, Higginson IJ. Benefits and costs of home palliative care compared with usual care for patients with advanced illness and their family caregivers. JAMA. 2014;311(10):1060-1.

21. Ali M, Capel M, Jones G, Gazi T. The importance of identifying preferred place of death. BMJ Support Palliat Care. 2015. doi: 000810.001136/ bmispcare-002015-000878. Ahead of print.

22. Nicholls SG, Quach P, von Elm E, Guttmann A, Moher D, Petersen I, Sorensen HT, Smeeth L, Langan SM, Benchimol El. The REporting of Studies Conducted Using Observational Routinely-Collected Health Data (RECORD) Statement: Methods for Arriving at Consensus and Developing Reporting Guidelines. PLoS One. 2015;10(5), e0125620

23. Gao W, Ho YK, Verne J, Gordon E, Higginson IJ. Geographical and temporal understanding in place of death in England (1984-2010): analysis of trends and associated factors to improve end-of-life Care (GUIDE Care). Health Serv Deliv Res. 2014;2(42). doi: 10.3310/hsdr02420.

24. McLennan D, Barnes H, Noble M, Davies J, Garratt E. The English Indices of Deprivation 2010. London: Department for Communities and Local Government; 2011.

25. Payne RA, Abel GA. UK indices of multiple deprivation-a way to make comparisons across constituent countries. Health Statistics Quarterly/Office for National Statistics. 2012:53(53):22-37.

26. Turner EL, Dobson JE, Pocock SJ. Categorisation of continuous risk factors in epidemiological publications: a survey of current practice. Epidemiol Perspect Innov. 2010;7:9

27. Gomes B, Higginson IJ, Calanzani N, Cohen J, Deliens L, Daveson BA, Bechinger-English D, Bausewein C, Ferreira PL, Toscani F, et al. Preferences for place of death if faced with advanced cancer: a population survey in England, Flanders, Germany, Italy, the Netherlands, Portugal and Spain. Ann Oncol. 2012;23(8):2006-15.

28. Higginson IJ, Astin P, Dolan S. Where do cancer patients die? Ten-year trends in the place of death of cancer patients in England. Palliat Med. 1998;12(5):353-63.

29. United Nations DoEaSA, Population Division. World Population Prospects: The 2015 Revision, DVD Edition. 2015. https://esa.un.org/unpd/wpp/. Accessed 26 Nov 2016

30. Zou G. A modified Poisson regression approach to prospective studies with binary data. Am J Epidemiol. 2004;159(7):702-6.

31. Hill AB. The environment and disease: association or causation? J R Soc Med. 2015;108(1):32-7.

32. Gao W, Verne J, Peacock J, Stiller C, Wells C, Greenough A, Higginson IJ. Place of death in children and young people with cancer and implications for end of life care: a population-based study in England, 1993-2014. BMC Cancer. 2016;16:727.

33. Muth C, van den Akker M, Blom JW, Mallen CD, Rochon J, Schellevis FG, Becker A, Beyer M, Gensichen J, Kirchner H, et al. The Ariadne principles: how to handle multimorbidity in primary care consultations. BMC Med. 2014:12:223.

34. Barnett K, Mercer SW, Norbury M, Watt G, Wyke S, Guthrie B. Epidemiology of multimorbidity and implications for health care, research, and medical education: a cross-sectional study. Lancet. 2012;380(9836):37-43. 
35. Mercer SW, Fitzpatrick B, Guthrie B, Fenwick E, Grieve E, Lawson K, Boyer N, McConnachie A, Lloyd SM, O'Brien R, et al. The CARE Plus study - a wholesystem intervention to improve quality of life of primary care patients with multimorbidity in areas of high socioeconomic deprivation: exploratory cluster randomised controlled trial and cost-utility analysis. BMC Med. 2016;14:88.

36. Mason B, Nanton V, Epiphaniou E, Murray SA, Donaldson A, Shipman C, Daveson BA, Harding R, Higginson IJ, Munday D, et al. 'My body's falling apart'. Understanding the experiences of patients with advanced multimorbidity to improve care: serial interviews with patients and carers. BMJ Support Palliat Care. 2016;6(1):60-5.

37. Afshar S, Roderick PJ, Kowal P, Dimitrov BD, Hill AG. Multimorbidity and the inequalities of global ageing: a cross-sectional study of 28 countries using the World Health Surveys. BMC Public Health. 2015;15:776.

38. Pefoyo AJ, Bronskill SE, Gruneir A, Calzavara A, Thavorn K, Petrosyan Y, Maxwell CJ, Bai Y, Wodchis WP. The increasing burden and complexity of multimorbidity. BMC Public Health. 2015;15:415.

39. Department of Health. Long Term Conditions Compendium of Information. London: Department of Health; 2012. https://www.gov.uk/government/ uploads/system/uploads/attachment_data/file/216528/dh_134486.pdf. Accessed 26 Sept 2016.

40. Maher TM. Idiopathic pulmonary fibrosis: pathobiology of novel approaches to treatment. Clin Chest Med. 2012;33(1):69-83.

41. Puhan MA, Garcia-Aymerich J, Frey M, ter Riet G, Anto JM, Agusti AG, Gomez FP, Rodriguez-Roisin R, Moons KG, Kessels AG, et al. Expansion of the prognostic assessment of patients with chronic obstructive pulmonary disease: the updated BODE index and the ADO index. Lancet. 2009;374(9691):704-11.

42. Gysels $M H$, Higginson IJ. The lived experience of breathlessness and its implications for care: a qualitative comparison in cancer, COPD, heart failure and MND. BMC Palliat Care. 2011;10:15.

43. Simon ST, Higginson IJ, Benalia H, Gysels M, Murtagh FE, Spicer J, Bausewein C. Episodes of breathlessness: types and patterns - a qualitative study exploring experiences of patients with advanced diseases. Palliat Med. 2013;27(6):524-32

44. Grudzen CR, Richardson LD, Morrison M, Cho E, Morrison RS. Palliative care needs of seriously ill, older adults presenting to the emergency department. Acad Emerg Med. 2010;17(11):1253-7.

45. Janssen DJ, Alsemgeest TP, Widdershoven GA, Wouters EF, Schols JM, Spruit MA. The last wish of a patient with end stage chronic obstructive pulmonary disease. BMJ. 2008;337:a2701.

46. Hui D, Bruera E. Integrating palliative care into the trajectory of cancer care. Nat Rev Clin Oncol. 2016:13(3):159-71.

47. Hui D, Kim YJ, Park JC, Zhang Y, Strasser F, Cherny N, Kaasa S, Davis MP, Bruera E. Integration of oncology and palliative care: a systematic review. Oncologist. 2015;20(1):77-83.

48. Farquhar MC, Prevost AT, McCrone P, Brafman-Price B, Bentley A, Higginson IJ, Todd CJ, Booth S. The clinical and cost effectiveness of a Breathlessness Intervention Service for patients with advanced non-malignant disease and their informal carers: mixed findings of a mixed method randomised controlled trial. Trials. 2016;17:185

49. Higginson IJ, Bausewein C, Reilly CC, Gao W, Gysels M, Dzingina M, McCrone P, Booth S, Jolley CJ, Moxham J. An integrated palliative and respiratory care service for patients with advanced disease and refractory breathlessness: a randomised controlled trial. Lancet Respir Med. 2014;2(12):979-87.

50. Bajwah S, Ross JR, Wells AU, Mohammed K, Oyebode C, Birring SS, Patel AS, Koffman J, Higginson IJ, Riley J. Palliative care for patients with advanced fibrotic lung disease: a randomised controlled phase $\|$ and feasibility trial of a community case conference intervention. Thorax. 2015;70(9):830-9.

51. Boland J, Owen J, Ainscough R, Mahdi H. Developing a service for patients with very severe chronic obstructive pulmonary disease (COPD) within resources. BMJ Support Palliat Care. 2014;4(2):196-201.

52. May P, Garrido MM, Cassel JB, Kelley AS, Meier DE, Normand C, Stefanis L, Smith TJ, Morrison RS. Palliative care teams' cost-saving effect is larger for cancer patients with higher numbers of comorbidities. Health Aff (Millwood). 2016;35(1):44-53.

53. Higginson IJ, Koffman J, Hopkins P, Prentice W, Burman R, Leonard S, Rumble C, Noble J, Dampier O, Bernal W, et al. Development and evaluation of the feasibility and effects on staff, patients, and families of a new tool, the Psychosocial Assessment and Communication Evaluation (PACE), to improve communication and palliative care in intensive care and during clinical uncertainty. BMC Med. 2013;11:213.

54. Mosenthal AC, Weissman DE, Curtis JR, Hays RM, Lustbader DR, Mulkerin C, Puntillo KA, Ray DE, Bassett R, Boss RD, et al. Integrating palliative care in the surgical and trauma intensive care unit: a report from the Improving Palliative Care in the Intensive Care Unit (IPAL-ICU) Project Advisory Board and the Center to Advance Palliative Care. Crit Care Med. 2012;40(4):1199-206.

55. McAllister DA, Morling JR, Fischbacher CM, MacNee W, Wild SH. Socioeconomic deprivation increases the effect of winter on admissions to hospital with COPD: retrospective analysis of 10 years of national hospitalisation data. Prim Care Respir J. 2013;22(3):296-9.

56. Higginson IJ, Jarman B, Astin P, Dolan S. Do social factors affect where patients die: an analysis of 10 years of cancer deaths in England. J Public Health Med. 1999;21(1):22-8.

57. Hunter LC, Lee RJ, Butcher I, Weir CJ, Fischbacher CM, McAllister D, Wild SH, Hewitt N, Hardie RM. Patient characteristics associated with risk of first hospital admission and readmission for acute exacerbation of chronic obstructive pulmonary disease (COPD) following primary care COPD diagnosis: a cohort study using linked electronic patient records. BMJ Open. 2016;6(1), e009121.

58. Jamieson AL, Harries TH, Thornton H, Crichton S, White P. Emergency admissions for COPD in an urban population: the role of population and primary care factors. COPD. 2015;12(6):606-12.

59. Lopez-Campos JL, Ruiz-Ramos M, Soriano JB. Mortality trends in chronic obstructive pulmonary disease in Europe, 1994-2010: a joinpoint regression analysis. Lancet Respir Med. 2014;2(1):54-62.

60. Gysels M, Higginson IJ. Access to services for patients with chronic obstructive pulmonary disease: the invisibility of breathlessness. J Pain Symptom Manage. 2008;36(5):451-60.

61. Henson LA, Higginson IJ, Daveson BA, Ellis-Smith C, Koffman J, Morgan M, Gao W. 'I'll be in a safe place': a qualitative study of the decisions taken by people with advanced cancer to seek emergency department care. BMJ Open. 2016;6(11):e012134.

62. Brown CE, Engelberg RA, Nielsen EL, Curtis JR. Palliative care for patients dying in the intensive care unit with chronic lung disease compared with metastatic cancer. Ann Am Thorac Soc. 2016;13(5):684-9.

63. Choi PP, Day A, Etchells E. Gaps in the care of patients admitted to hospital with an exacerbation of chronic obstructive pulmonary disease. CMAJ. 2004 170(9):1409-13.

64. Elkington $\mathrm{H}$, White $\mathrm{P}$, Addington-Hall J, Higgs $\mathrm{R}$, Edmonds $\mathrm{P}$. The healthcare needs of chronic obstructive pulmonary disease patients in the last year of life. Palliat Med. 2005;19(6):485-91.

\section{Submit your next manuscript to BioMed Central and we will help you at every step:}

- We accept pre-submission inquiries

- Our selector tool helps you to find the most relevant journal

- We provide round the clock customer support

- Convenient online submission

- Thorough peer review

- Inclusion in PubMed and all major indexing services

- Maximum visibility for your research

Submit your manuscript at www.biomedcentral.com/submit
) Biomed Central 